OPEN ACCESS

Edited by:

Tong-Bao Liu,

Southwest University, China

Reviewed by:

James Kronstad,

University of British Columbia, Canada

Changbin Chen,

Institut Pasteur of Shanghai (CAS),

China

*Correspondence:

Chaoyang Xue

xuech@njms.rutgers.edu

Specialty section:

This article was submitted to

Fungal Pathogenesis,

a section of the journal

Frontiers in Cellular and

Infection Microbiology

Received: 12 September 2021

Accepted: 25 October 2021

Published: 10 November 2021

Citation:

Cao C and Xue C (2021) More Than Just Cleaning: Ubiquitin-Mediated

Proteolysis in Fungal Pathogenesis.

Front. Cell. Infect. Microbiol. 11:774613.

doi: 10.3389/fcimb.2021.774613

\section{More Than Just Cleaning: Ubiquitin-Mediated Proteolysis in Fungal Pathogenesis}

\author{
Chengjun $\mathrm{Cao}^{1}$ and Chaoyang Xue $\mathrm{X}^{1,2,3 *}$ \\ 1 Public Health Research Institute, Rutgers University, New Brunswick, NJ, United States, 2 Department of Microbiology, \\ Biochemistry and Molecular Genetics, Rutgers University, Newark, NJ, United States, ${ }^{3}$ Rutgers Center for Lipid Research, \\ Rutgers University, New Brunswick, NJ, United States
}

Ubiquitin-proteasome mediated protein turnover is an important regulatory mechanism of cellular function in eukaryotes. Extensive studies have linked the ubiquitin-proteasome system (UPS) to human diseases, and an array of proteasome inhibitors have been successfully developed for cancer therapy. Although still an emerging field, research on UPS regulation of fungal development and virulence has been rapidly advancing and has generated considerable excitement in its potential as a target for novel drugs. In this review, we summarize UPS composition and regulatory function in pathogenic fungi, especially in stress responses, host adaption, and fungal pathogenesis. Emphasis will be given to UPS regulation of pathogenic factors that are important for fungal pathogenesis. We also discuss future potential therapeutic strategies for fungal infections based on targeting UPS pathways.

Keywords: ubiquitin-proteasome system (UPS), ubiquitin, fungal pathogens, E3 ligase, drug discovery

\section{OVERVIEW OF THE UBIQUITIN-PROTEASOME SYSTEM}

Ubiquitin exists in all eukaryotic cells and it modifies proteins for proteasomal degradation and non-proteolytic functions (Finley et al., 2012). The ubiquitin-proteasome system (UPS) is important for a multitude of cellular processes due to its capability to rapidly and selectively turnover intracellular proteins. The UPS involves ubiquitin activation, ubiquitin-substrate conjugation, ubiquitin receptor recognition, and proteasomal degradation (Glickman and Ciechanover, 2002; Finley et al., 2012) (Figure 1). Protein ubiquitination is initiated by the ubiquitin-activating enzyme $\mathrm{E} 1$ in an ATP-dependent manner. Activated ubiquitin is transferred to the ubiquitin-conjugating enzyme E2. Thereafter, ubiquitin ligase E3 binds to E2 and catalyzes the covalent attachment of ubiquitin to the lysine residues of target substrates. Polyubiquitin chains are synthesized after several rounds of conjugation. Polyubiquitinated proteins are directly recognized by the $26 \mathrm{~S}$ proteasome or delivered to the proteasome by ubiquitin receptor proteins (Elsasser and Finley, 2005; Finley et al., 2012), and then are degraded into small peptides and reusable ubiquitin (Glickman and Ciechanover, 2002). Protein ubiquitination is a reversible post-translational modification. Deubiquitinating enzymes (DUB) catalyze protein deubiquitination to prevent proteins from $26 \mathrm{~S}$ proteasome-mediated degradation and maintain ubiquitin homeostasis in cells (Komander et al., 2009). 
Given the ubiquity of the UPS that targets a wide array of proteins in various processes, it is not surprising that aberrations in the UPS have been implicated in human diseases including cancer, neurodegeneration, metabolic disorders, cardiovascular disorders, and inflammation (Glickman and Ciechanover, 2002; Zheng et al., 2016; Li et al., 2018; Senft et al., 2018; Gupta et al., 2021). Certain cancers arise from stabilization of pro-oncogenic proteins and pathways such as growth-promoting factors (Bahram et al., 2000; Yada et al., 2004; Yumimoto and Nakayama, 2020) or destabilization of tumor suppressors such as p53 and p27 (Slingerland and Pagano, 2000; Devine and Dai, 2013). The accumulation of neurotoxic proteins causes neurodegenerative diseases including Alzheimer's disease, Parkinson's disease, and Huntington's disease, etc. (Popovic et al., 2014; Celebi et al., 2020). Both ubiquitination and the impairment of proteasomal function contribute to ubiquitinated protein accumulation in the cytoplasm (Zheng et al., 2016; Celebi et al., 2020). A number of compounds have been reported to target the UPS as a new class of potential therapeutics for human diseases (Yang et al., 2007; Devine and Dai, 2013; Liu et al., 2015; Hosseini et al., 2019; Wang et al., 2019a). Some proteasome inhibitors have been approved for cancer treatment, e.g., multiple myeloma and mantle cell lymphoma (Sherman and $\mathrm{Li}, 2020)$. The roles of various components of the UPS have been widely studied in humans and the model yeast Saccharomyces cerevisiae. However, studies on the role of UPS components in fungal pathogens remain limited.

Fungal diseases are serious threats to both agriculture and human health. They are difficult to treat because fungi are eukaryotic cells that share much of their cellular machinery with hosts. There are currently no vaccines in clinical use to combat fungal infections, and our armamentarium of antifungal drugs is limited compared to antibiotics and even antiviral agents (Rodrigues and Nosanchuk, 2020; Johnson, 2021). Thus, development of new treatment options is critical for controlling mycoses. The UPS tightly regulates degradation of cellular proteins that play important roles in a variety of cellular pathways during the cell life and host adaptation in fungi. Therefore, understanding the regulation of the UPS in fungal pathogenesis may be valuable for the future development of novel therapeutic approaches. Here, we will describe the role of various components of the UPS in fungal morphogenesis, stress response, host adaptation and fungal virulence.

\section{UBIQUITIN}

Ubiquitin is a small polypeptide of 76 amino acids that is highly conserved in all eukaryotes (Ozkaynak et al., 1987; Hershko and Ciechanover, 1998). Ubiquitin is typically linked to protein lysine residues, as well as lysines on ubiquitin itself, allowing for different types of modification, such as monoubiquitination, multiubiquitination, and polyubiquitination (Peng et al., 2003; Komander and Rape, 2012) (Figure 2). The fates of ubiquitinated proteins are determined by the types of ubiquitin modification: proteins modified by K48-linked polyubiquitin chain can be preferentially degraded by the proteasome, whereas multi- or monoubiquitination often mediates nonproteolytic mechanisms such as DNA repair, protein binding, subcellular localization, and the trafficking of membrane proteins (Hicke, 2001; Kravtsova-Ivantsiv et al., 2009; Ziv et al., 2011).

In $S$. cerevisiae, ubiquitin is produced by cleavage from precursor proteins that are encoded by a family of natural gene fusions (Ozkaynak et al., 1987). UBI1-3 genes encode hybrid proteins, in which ubiquitin units fuse to unrelated peptide sequences. UBI4 encodes a polyubiquitin that contains five consecutive ubiquitin repeats and is highly induced under stress conditions (Finley et al., 1987; Fraser et al., 1991). In fungal pathogens, ubiquitin genes have been shown to play an important role in fungal development, stress resistance, and fungal virulence (Roig and Gozalbo, 2003; Oh et al., 2012; Chen et al., 2018). Two ubiquitin genes have been identified in Candida albicans (Sepulveda et al., 1996; Roig et al., 2000), an opportunistic fungal pathogen that can switch among different morphologies to adapt to various environmental stimuli (Huang, 2012). The UBI3 gene encodes a hybrid ubiquitin fusion protein which is essential for growth of C. albicans (Roig and Gozalbo, 2002). The polyubiquitin gene UBI4 contains three ubiquitin repeats and is involved in fungal growth and virulence (Sepulveda et al., 1996; Leach et al., 2011). Deletion of UBI4 in C. albicans induces morphological transition from yeast to hyphae, which is important for the pathogenicity of $C$. albicans (Roig and Gozalbo, 2003; Yang D. et al., 2020). The ubi4 $\Delta / \Delta$ mutant displays a cell wall biosynthesis defect when exposed to a number of cell wall stresses including treatment with the antifungal drug caspofungin (Leach et al., 2011). The observation that $u b i 4 \Delta / \Delta$ cells are more sensitive to peroxide is significant because reactive oxygen species contribute to the antimicrobial activity of host immune cells (Miller and Britigan, 1997; Leach et al., 2011). Inactivation of UBI4 significantly attenuates virulence in a murine model of systemic candidiasis (Leach et al., 2011).

There are two ubiquitin encoding genes (UBI1 and UBI4) in Cryptococcus neoformans (Spitzer and Spitzer, 1995), a human pathogen that commonly causes life-threatening meningoencephalitis in immunocompromised individuals (Mitchell and Perfect, 1995). UBI1 encodes a hybrid protein that fuses with ribosomal protein Rpl40a and shares sequence similarity with UBI1 in S. cerevisiae. UBI4 encodes a polyubiquitin precursor containing five ubiquitin repeats (Spitzer and Spitzer, 1995). Deletion of UBI1 results in a vegetative growth defect, morphological changes, a melanin production defect, decreased intracellular survival inside macrophages and virulence attenuation during infection (Zhao et al., 2020). Reconstitution of the full length of UBI1 or the C-terminal Rpl40a could both reverse the phenotypes of $u b i 1 \Delta$ mutation, indicating a role for Ubil in cryptococcal ribosome biogenesis (Zhao et al., 2020). Deletion of UBI1 also led to the differential expression of ubiquitin-conjugating enzymes (Zhao et al., 2020), suggesting a regulatory function for Ubil in the UPS, but the role of ubiquitin moiety in the pathogenicity of $C$. neoformans requires further investigation (Zhao et al., 2020). 


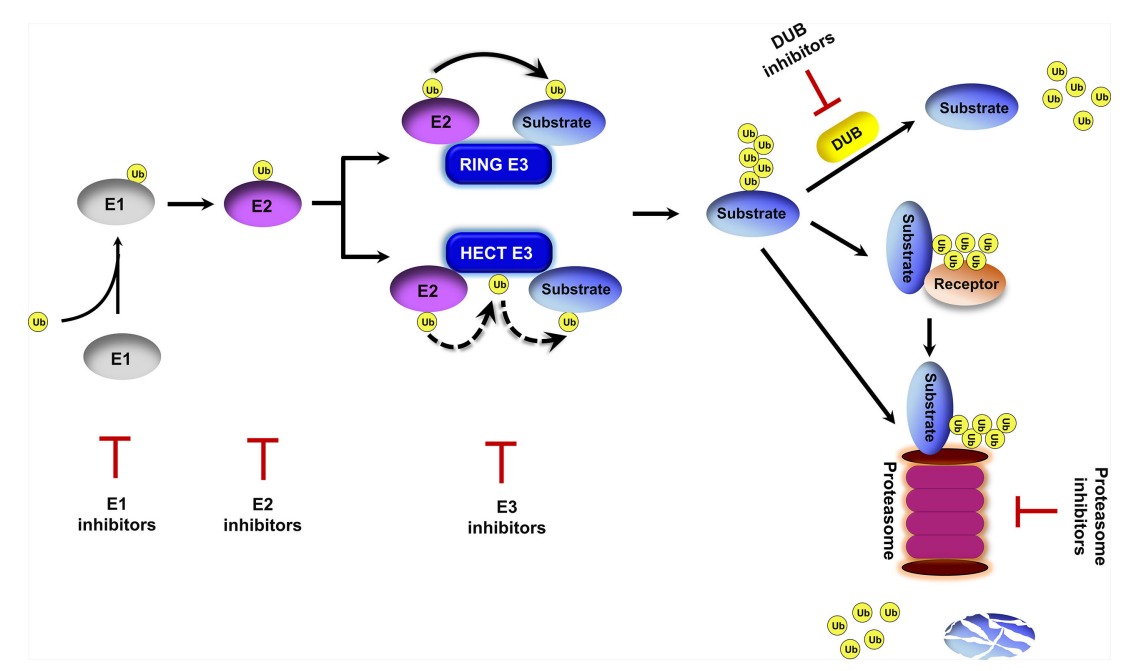

FIGURE 1 | Overview of the ubiquitin proteasome system. Ubiquitin is activated by an E1 enzyme and transferred to an E2 enzyme. The activated ubiquitin is then transferred from the E2 to the substrate in a repeated process mediated by an E3 ubiquitin ligase to form a polyubiquitin chain on the protein substrate. This ubiquitination process can be reversed by deubiquitinating enzymes (DUBs). Polyubiquitinated substrates are either delivered to the proteasome by ubiquitin receptors or directly recognized by the proteasome for cleavage into small peptides and the release of ubiquitin molecules. Inhibitors targeting E1s, E2s, E3s, DUBs and the proteasome have been proposed.

A $6 \quad 11$

B

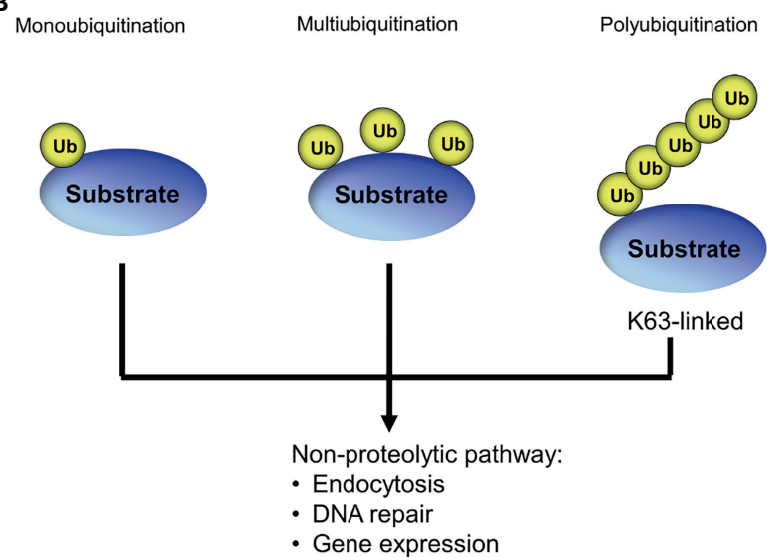

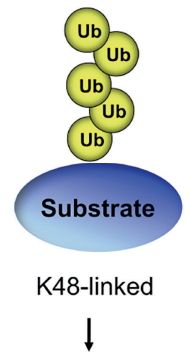

Proteasomal degradation

FIGURE 2 | Different forms of ubiquitin modification. (A) Seven specific lysine residues in ubiquitin used for polyubiquitin chain formation. (B) Different types of ubiquitination lead to different biological outcomes.

Deletion of the polyubiquitin gene $M G G \_01282$ resulted in abnormal morphology and virulence defects in the filamentous ascomycete fungus Magnaporthe oryzae, the leading cause of fungal diseases in rice globally (Oh et al., 2012). Likewise, the polyubiquitin gene CPUBI4 is required for fungal development, stress adaptation, and virulence in Cryphonectria parasitica, a phytopathogenic filamentous fungus that causes chestnut blight disease (Chen et al., 2018). The role of polyubiquitin genes in insect fungal pathogens were also explored recently (Wang et al., 2019b; Wang et al., 2020). Polyubiquitin genes were functionally characterized via gene deletion in Metarhizium robertsii and Beauveria bassiana. MrUBI4 is involved in UV stress and the heat-shock response in M. robertsii (Wang et al., 2019b). Deletion of UBI4 leads to a defect in stress tolerance and 
attenuated virulence in B. bassiana (Wang et al., 2020). In all, ubiquitin genes play important roles in fungal pathogenesis.

\section{UBIQUITIN-ACTIVATING ENZYMES (E1S)}

The ubiquitination cascade is initialed by the highly conserved ubiquitin-activating enzyme (E1) that catalyzes covalent bond formation between the active site cysteine of the E1 and the C-terminal glycine residue of ubiquitin (McGrath et al., 1991; Pickart, 2001). Most species have single E1 enzyme, and its activity is necessary for all subsequent steps in ubiquitination (McGrath et al., 1991; Watts et al., 2003; Kulkarni and Smith, 2008). In S. cerevisiae, E1 is encoded by an essential gene UBA1 (McGrath et al., 1991), and inactivation of UBA1 dramatically reduces ubiquitin conjugation (Ghaboosi and Deshaies, 2007). Because of the conservative nature of the E1 in different organisms, their essentiality is likely also shared in pathogenic fungi. Therefore, despite the E1 in S. cerevisiae has been well characterized, there is very limited studies on its function in fungal pathogens. In the yeast pathogen $C$. neoformans, the cAMP/PKA signaling plays a critical role in capsule and melanin formation, and is important for its pathogenicity (D'Souza et al., 2001). Analysis of the PKA-regulated proteome identified the role of the ubiquitin-proteasome pathway in capsule regulation. Induction of Pka1 leads to decreased protein level of the single E1 in C. neoformans (Geddes et al., 2016).

\section{UBIQUITIN-CONJUGATING ENZYMES (E2S)}

The ubiquitin-conjugating enzyme $\mathrm{E} 2$ is at the center of the E1-E2-E3 enzymatic cascade. E2s interact with E1 and E3 and transfer ubiquitin from E1 to the substrate (Ye and Rape, 2009). E2s belong to the E2 superfamily which contains a highly conserved ubiquitin-conjugating (UBC) domain (Ye and Rape, 2009). A total of $13 \mathrm{E} 2$ genes have been found in S. cerevisiae (Finley et al., 2012), 40 in A. thaliana (Kraft et al., 2005), and 37 in humans (van Wijk and Timmers, 2010). E2 enzymes have the ability to control the topology of ubiquitin conjugates and to determine the fate of labeled proteins to either degradation or nonproteolytic processes (van Wijk and Timmers, 2010). Multiple E2 enzymes can be involved in ubiquitination of a single substrate, such as the Mat $\alpha 2$ transcriptional regulator in $S$. cerevisiae that is controlled by $4 \mathrm{E} 2 \mathrm{~s}$ (Chen et al., 1993). A single E2 can combine with different types of E3s that recognize and select distinct substrates (Finley et al., 2012). Interestingly, E2s have also been shown to directly ubiquitinate endogenous substrates independent of an E3 ligase (Berleth and Pickart, 1996; Kraft et al., 2005). Several studies on E2 enzymes in plants have revealed the role of E2 enzymes in host defense against fungal infection (Finley et al., 2012; Liu et al., 2020). Plant E2s are involved in abiotic stress responses, including osmotic stress tolerance (Zhou et al., 2010; Chung et al., 2013), heat shock responses (Feussner et al., 1997), and oxidative stress responses (Zhou et al., 2010). E2 enzymes also play important roles in plant immune responses and DNA repair (Finley et al., 2012; Liu et al., 2020). Inactivation of the ubiquitin-conjugating enzyme 4 (Tau4) in bread wheat Triticum aestivum increases host defense against the phytopathogen Zymoseptoria tritici (Millyard et al., 2016). Ectopic expression of the E2 gene OgUBC1 from rice confers resistance against Botrytis cinerea infection in A. thaliana (Jeon et al., 2012). The ubiquitinconjugating enzyme Rad6 is conserved amongst eukaryotes (Huang et al., 1997; Worthylake et al., 1998). Rad6 in C. albicans protects the fungus against UV damage and negatively regulates hyphal development (Leng et al., 2000). MoRad6 in M. oryzae is essential for fungal development and pathogenicity (Shi et al., 2016). There is no published work on UBC domain containing proteins in C. neoformans or Aspergillus fumigatus. Sequence homology searching revealed 18 proteins containing the UBC domain in C. neoformans genome (https://fungidb.org).

\section{UBIQUITIN LIGASES (E3S)}

Ubiquitin ligases (E3s) form a large and diverse family that recognize specific substrate proteins. The E3 ligases bind E2s and substrates to facilitate substrate-specific ubiquitination (Hicke and Dunn, 2003; Finley et al., 2012). E3s are classified into two major classes, which catalyze ubiquitin transfer from E2 to substrate via different mechanisms. These two classes are either RING (really interesting new genes) domain-containing E3s, or HECT (homologous to E6-AP C-terminus) domain E3s (Huibregtse et al., 1995; Bernassola et al., 2008). HECT E3s form an intermediate thioester bond between the active site cysteine in the HECT domain and ubiquitin received from E2 and transfer ubiquitin to substrate from the HECT E3-Ub (Huibregtse et al., 1995). RING E3s catalyze the direct transfer of ubiquitin from the E2 to substrates by bridging the interaction between E2 and substrate proteins (Deshaies and Joazeiro, 2009). In addition, RBR proteins (RING-between-RINGs domain E3, a subclass of RING domain E3s) bind E2s with one RING domain and transfer ubiquitin to the other RING domain before its transfer to the substrate, therefore apparently functioning as RING/HECT hybrids (Wenzel et al., 2011; Wenzel and Klevit, 2012). There are only five HECT domain E3s among 60-100 putative E3s in yeast (Finley et al., 2012) that function in diverse processes ranging from protein degradation, metabolic process, endocytosis, and cell cycle progression (Pesin and Orr-Weaver, 2008; Rotin and Kumar, 2009; Finley et al., 2012). Most identified E3s belong to the class of RING domain E3s. Cullin-RING ligases (CRLs) are the largest group of ubiquitin ligases in eukaryotes (Finley et al., 2012). The SCF (Skp1-Cullin-F-box protein) ligase is the typical CRL ligase, in which the cullin protein Cdc53 binds to the small RING domain subunit in Rbx1 with its C-terminal regions and binds to F-box proteins through the linker protein Skp1 with the N- terminal regions (Finley et al., 2012). Substrates of SCF ligases are phosphorylated to create a binding surface for F-box motif recognition (Feldman et al., 1997; Skowyra et al., 1997). 
The role of E3 ligases has been widely studied in human health and disease, including cancer, neurodegenerative disease, and neurological syndromes, with a view to develop new clinical therapies (Huang et al., 2016; Mao et al., 2018; Pan, 2020; Wang Y. et al., 2020; Goto et al., 2021). Studies on E3s in pathogenic fungi have revealed that many E3s are required for fungal virulence, as reviewed by (Liu and Xue, 2011). These studies focus on the homologs of Grr1 and Cdc4, which are the two best studied SCF ligases in S. cerevisiae. SCF(Grr1) induces degradation of the Mth1 and G1 cyclins $\mathrm{Cln} 1$ and $\mathrm{Cln} 2$ to control glucose sensing and the cell cycle in S. cerevisiae (Seol et al., 1999; Skowyra et al., 1999; Flick et al., 2003). SCF(Cdc4) controls cell cycle transitions and nutrient responses by recruiting downstream phosphorylated substrates, such as the cyclin-dependent kinase inhibitor Sicl and the transcription factor Gcn4 (Feldman et al., 1997; Skowyra et al., 1997; Meimoun et al., 2000; Chi et al., 2001). The role of other major subunit of SCF complex, such as cullin Cdc53, has also been reported in pathogenic fungi (Trunk et al., 2009; Sela et al., 2012). Cdc53 is an essential gene in C. albicans and negatively regulates filamentation when under the control of a tetracyclinedependent promoter (Trunk et al., 2009). Modification of Cdc53 by the ubiquitin-related protein NEDD8/Rub1 (neddylation, ubiquitin-related protein) is also involved in morphogenetic phenotype (Sela et al., 2012). Either deletion of CaRUB1 or mutation of the neddylation target site in CaCdc53 showed filamentous growth, indicating that $\mathrm{CaCdc53}$ neddylation regulates Candida dimorphic switch (Sela et al., 2012).

Grr1 contains an F-box domain and a leucine rich repeat (LRR) at its C-terminus. Homologs of Grr1 have been reported in several important fungal pathogens (Liu and Xue, 2011). Fbp1 is essential for Cryptococcus virulence. Even though the $f b p 1 \Delta$ mutant produces normal classical virulence factors, including capsule and melanin production, mice infected with $f b p 1 \Delta$ showed a low persistence of fungal burden throughout infection, (Liu et al., 2011; Liu and Xue, 2014). Further studies found that $f b p 1 \Delta$-infected mice developed a robust Th1 and Th17 host protective immune response that helps contain yeast cells in the lung and prevent them from dissemination to maintain the long-term survival of the host (Masso-Silva et al., 2018). Mice challenged with heat-killed $f b p 1 \Delta$ cells (HK-fbp $1 \Delta$ ) also can develop a robust Th1 response that confers protection against infection with the virulent wild type strain (Masso-Silva et al., 2018). Interestingly, vaccination of $\mathrm{HK}-f b p 1 \Delta$ cells induces crossprotection against challenge with other invasive fungal pathogens, including C. gattii and A. fumigatus. The vaccine protection is effective even in mice depleted of $\mathrm{CD} 4^{+} \mathrm{T}$ cells, a condition mimics HIV/AIDS-induced immune deficiency (Wang Y. et al., 2019). Several potential substrates of Fbp1 have been identified in C. neoformans (Liu et al., 2011; Liu and Xue, 2014; Han et al., 2020; Fan and Liu, 2021). One of them, a Cdk-related kinase Crk1, has been found to be involved in meiosis regulation (Liu et al., 2011; Liu and Shen, 2011). Another substrate Isc1 (the inositol phosphosphingolipid-phospholipase C1) is required for fungal survival inside macrophage cells (Liu and Xue, 2014). Several additional Fbp1 interacting proteins, including mannoprotein
Cmp1 and vacuolar morphogenesis protein Vlp1, has also been considered as potential substrates of Fbpl based on protein pulldown assays, although their functional verification remains missing. Both proteins are required for pathogenicity of $C$. neoformans, as the $v l p 1 \Delta$ mutant is avirulent and the $c m p 1 \Delta$ mutant or the CMP1 overexpression strain shows virulence attenuation in a murine infection model of systemic cryptococcosis (Han et al., 2020; Fan and Liu, 2021). Besides Fbp1, there are 19 additional F-box proteins in C. neoformans that remain to be studied.

In C. albicans, Grr1 negatively regulates pseudohyphal development (Butler et al., 2006), an important fungal virulence factor implicated in the cell cycle (Bachewich and Whiteway, 2005; Bensen et al., 2005; Chapa y Lazo et al., 2005; Li et al., 2006). A. fumigatus GrrA shares structural similarity to Fbp1 of C. neoformans. Deletion of GRRA in A. fumigatus has no impact on its virulence, indicating the role of Grr1 homologs in virulence might vary in different pathogenic fungi (Johnk et al., 2016). In Gibberella zeae, an important plant pathogen and fungal mycotoxins producer, the Grr1 homolog Fbpl is a versatile F-box protein involved in the mycelial growth, sexual reproduction, and virulence. Deletion of FBP1 impairs the ability of G. zeae to colonize plant cells, which leads to attenuated virulence with mild disease (Han et al., 2007). Two homologs of Grr1 have been identified in M. oryzae. Both of them are required for fungal pathogenicity based on mutagenesis studies (Sweigard et al., 1998; Guo et al., 2015).

Cdc4 homologs have also been well characterized in a number of fungal pathogens. Cdc4 contains an F-box domain and a WD40 domain that is important for interaction with its downstream substrates. SCF $(\mathrm{Cdc} 4)$ plays critical roles in C. albicans morphogenesis and biofilm formation (Atir-Lande et al., 2005; Shieh et al., 2005; Chin et al., 2013; Tseng et al., 2015). Deletion of CDC4 promotes hyphae growth, especially of true hyphae rather than pseudohyphal development, which is different from Grr1 in this fungus. Hyphae growth in the $c d c 4 \Delta / \Delta$ mutant is independent of the transcription factors Efg1 and Cph1 or G1 cyclins (Atir-Lande et al., 2005). Multiple Cdc4 substrates important for Cdc4-mediated morphogenesis have been identified. Sol1, a homologue of Sic1 (a substrate of Cdc4 in S. cerevisiae), has been identified as a substrate of Cdc4 in $C$. albicans and it involved in C. albicans morphogenesis. Another $\mathrm{SCF}(\mathrm{Cdc} 4)$ substrate, Ume6, has been found to be critical target of $\mathrm{SCF}(\mathrm{Cdc} 4)$ and responsible for the hyphae formation of $c d c 4 \Delta / \Delta$ mutant in $C$. albicans. The $c d c 4 \Delta / \Delta u m e 6 \Delta / \Delta$ double mutant has reduced filamentous growth, but more pseudohyphal development than the $c d c 4 \Delta / \Delta$ single mutant (Mendelsohn et al., 2017). Consistent with this observation, deletion of UME6 blocks the increased expression of hypha-specific genes in the $c d c 4 \Delta / \Delta$ mutant background. The $c d c 4 \Delta / \Delta$ ume $6 \Delta / \Delta$ soll $\Delta / \Delta$ triple mutant lost the ability for filamentous growth, while can be restored by introducing of UME6, indicating the important role of Ume6 in Cdc4-mediated hyphal formation (Mendelsohn et al., 2017). Thr1 has also been identified as a Cdc4 substrate by in vitro affinity purification in C. albicans (Tseng et al., 2010). Thr1 is a homoserine kinase and its stability is dependent on Cdc4. The thr $1 \Delta / \Delta$ mutant accumulates toxic homoserine and 
shows virulence attenuation (Kingsbury and McCusker, 2010a; Kingsbury and McCusker, 2010b). Similar to Sol1, Thr1 positively modulates hyphal formation (Lee et al., 2018). In addition, Thr1 negatively regulates biofilm formation in C. albicans (Tseng et al., 2015).

There are over 20 proteins containing the F-box domain in the genomes of Aspergillus spp. e.g., human pathogen A. fumigatus and mycotoxin producing plant pathogen $A$. flavus (Frawley and Bayram, 2020). A total of 26 F-box proteins in A. fumigatus and 30 in A. flavus have been detected by immunoprecipitation of the HA-tagged SkpA adaptor protein during vegetative growth. Analysis of fungal F-box proteins has revealed an interaction network in the presence of various exogenous stress conditions, including osmotic and oxidative stresses, the cell wall stressor Congo red, and the antifungal drug Amphotericin B or Miconazole (Frawley and Bayram, 2020). While some F-box proteins were identified to interact with SkpA across all these different stress conditions, other F-box proteins were only detected under one condition, suggesting they may be specific to one particular stress. Two F-box proteins (Fbx20 and Fbx45) in A. fumigatus and three Fbox proteins (Fbx1, Fbx11 and Fbx45) in A. flavus interact with SkpA only in response to Amphotericin B. Fbx45 was detected in both species in response to Amphotericin B. Orthologs of Fbx45 are conserved among Aspergillus species and do not exist in humans, suggesting that Fbx45 could be a potential anti-fungal target (Frawley and Bayram, 2020). Fbx15 is specific to filamentous fungi. Deletion of the F-box domain in Fbx15 impairs stress resistance, similar to the $f b x 15 \Delta$ mutant, suggesting that Fbx15 functions as a subunit of the $\mathrm{SCF}(\mathrm{Fbx} 15) \mathrm{E} 3$ ligase and is critical for stress tolerance in A. fumigatus. The fbx15 15 mutant cells are cleared at an early stage of infection and the infected animals show no disease symptom in a mouse model of aspergillosis, indicating that Fbx15 is required for Aspergillus virulence (Johnk et al., 2016).

Other F-box proteins, such as Frpl in the root-infecting fungus Fusarium oxysporum and several F-box proteins in $M$. oryzae, including MoFwd1, MoCdc4 and MoFbx15, and HECT type E3 Upl3 have also been reported to be required for fungal virulence (Duyvesteijn et al., 2005; Jonkers et al., 2011; Shi et al., 2019; Li et al., 2020).

Overall, because the F-box protein family has large members with diverse functions and the fact that the F-box protein determines the substrate specificity, much of attention on the E3 ligase studies in fungal pathogens have been focusing on function of F-box proteins and their substrates. Understanding the function of F-box proteins and their substrates will lead to a better understanding of the UPS mediated functional regulation, including fungal development and pathogenesis. Identification of F-box proteins that are important for fungal virulence may also lead to development of novel drug targets, hence is highly significant.

\section{DEUBIQUITINATING ENZYMES (DUBS)}

Deubiquitinating enzymes (DUBs) reverse ubiquitination by hydrolyzing polyubiquitin chains (Amerik and Hochstrasser, 2004; Reyes-Turcu et al., 2009). DUBs are an important part of the UPS in multiple fundamental cellular processes, including DNA damage repair, protein quality control and cell cycle regulation (Komander, 2009; He et al., 2016; Kee and Huang, 2016). DUBs have been associated with human pathologies including cancer, neurodegenerative diseases and infectious diseases (Nanduri et al., 2013; Heideker and Wertz, 2015; He et al., 2016; Das et al., 2020). DUBs are involved in the regulation of various stress responses in S. cerevisiae (Auesukaree et al., 2009; Mat Nanyan et al., 2020) and C. neoformans (Liu et al., 2008; Fang et al., 2012). There are 19 putative DUB proteins in $C$. neoformans and most of them are required for its pathogenesis (Liu et al., 2008; Fang et al., 2012). Deletion of UBP5 elevates sensitivity to external stress such as high temperature, reactive oxygen species, osmotic changes, or antifungal agents. Ubp5 and Doa4 are important for Cryptococcus virulence factor production (capsule and melanin) and in vivo fungal virulence (Fang et al., 2012). Several studies have identified the role of DUBs in the pathogenic fungus $M$. oryzae. Deletion of MoUBP14 resulted in virulence attenuation and phenotypic defects, including stress sensitivity and reduced conidiation (Wang et al., 2018). MoUbp4 and MoUbp8 are required for infection-related morphogenesis and pathogenicity. The moubp $4 \Delta$ and moubp $8 \Delta$ mutants show reduced mycelial growth, which blocks penetration and invasive growth and reduces pathogenicity (Que et al., 2020; Yang J. et al., 2020). Overall, the deubiquitination process provides another layer of post-translation regulation that has been shown to be important for fungal pathogenesis.

\section{UBIQUITIN RECEPTORS}

How do proteasomes specifically acquire ubiquitinated proteins? Studies in $S$. cerevisiae have revealed that several ubiquitin receptors, including $\operatorname{Rad} 23$, Ddi1, and Dsk2, play important roles in shuttling substrates to the proteasome (Verma et al., 2004; Dantuma et al., 2009). These three ubiquitin receptors contain both ubiquitin-like (UBL) domains and ubiquitinassociated (UBA) domains. Ubiquitin receptors specifically bind to polyubiquitin chains of target proteins through UBA domains and interact with the proteasome through their UBL domain (Dantuma et al., 2009). In yeast, Rad23 and Ddi1 are two DNA damage-inducible proteins (Liu et al., 1997; Jelinsky et al., 2000) and Dsk2 is required for the duplication of microtubuleorganizing centers (Biggins et al., 1996). Rad23 contributes to both nucleotide excision repair (NER) and protein turnover by directing proteins to the proteasome from yeast to human (Dantuma et al., 2009; Farmer et al., 2010; Lahari et al., 2017). $\operatorname{Rad} 23$ has a UBL domain and two UBA domains (UBA1 and UBA2). Its UBA2 domain binds to ubiquitin molecules and the UBL domain binds to proteasome (Dantuma et al., 2009). In addition, it also contains a XPCB (Rad4-binding) domain that is important for NER. In C. albicans, either deletion or overexpression of RAD23 leads to increased UV sensitivity. The $\mathrm{rad} 23 \Delta / \Delta$ mutant showed hypervirulence in a murine infection model (Feng et al., 2020). Rad4 is critical in the $\operatorname{Rad} 23$ mediated response to UV and has similar functions 
regulating cell morphogenesis and biofilm formation, yet it does not play an important role in fungal virulence. Since Rad4 is a key component of the NER pathway and is disposable for fungal virulence, $\operatorname{Rad} 23$ mediated virulence suppression is likely due to its role in protein degradation, rather than the NER pathway in C. albicans (Feng et al., 2020). Deletion of different domains to uncouple the two functions of $\operatorname{Rad} 23$ has also been reported in C. neoformans. In the wax moth (Galleria mellonella) larvae infection model, the UBA2 domain is required for virulence and the XPCB domain is not involved in fungal virulence in C. neoformans, indicating that the role of $\operatorname{Rad} 23$ in virulence is also due to its function in protein turnover rather than NER. How the ubiquitin receptor $\operatorname{Rad} 23$ regulates virulence remains to be understood (Verma et al., 2019).

\section{THE PROTEASOME}

The proteasome is found in all eukaryotes and has been extensively characterized in S. cerevisiae (Finley et al., 2012). The proteasome is a highly conserved protein complex composed of a catalytic 20S core particle and associated 19S regulatory particles. The regulatory particles recognize ubiquitin-protein conjugates or shuttle receptors with their cargo of ubiquitinated substrates, deubiquitinate substrates, and translocate proteins into the core particle for hydrolysis. The core particle contains interior proteolytic active sites that control proteolysis (Finley, 2009; Finley et al., 2012; Enenkel, 2014). Although the proteasome has not been extensively characterized in pathogenic fungi, it has been implicated in fungal virulence (Geddes et al., 2016; Hossain et al., 2020). Proteasome inhibitors targeting the $20 \mathrm{~S}$ subunit of the proteasome were used to identify the role of the proteasome in fungal virulence. Commonly used proteasome inhibitors are bortezomib, a boronic acid-based inhibitor widely used for the treatment of multiple myeloma and hematologic malignancy (Nunes and Annunziata, 2017), and MG132, a synthesized peptide aldehyde commonly used for in vitro studies (Lee and Goldberg, 1998).

Among the 33 predicted proteasome subunit genes in C. albicans, 28 are essential subunits. Genetic depletion of most proteasome subunits induces filamentation, demonstrating that proteasome function is essential for C. albicans growth and morphogenesis (Hossain et al., 2020). Proteasome inhibitor treatment also produces filaments that share structural similarities with the $h s p 90 \Delta / \Delta$ mutant in C. albicans. Inhibition of the proteasome relieves Hsp90-mediated repression of cAMPPKA signaling to induce morphogenesis (Hossain et al., 2020). To assess the role of the proteasome in the filamentation of other Candida species, including C. dubliniensis, C. tropicalis, C. krusei, C. parapsilosis, and C. auris, Bortezomib has been used to treat these fungi. Bortezomib treatment results indicate that the proteasome has conserved roles in regulating fungal morphogenesis across diverse fungal species (Hossain et al., 2020). Bortezomib treatment impairs the growth of $C$. neoformans strains and reduces capsule size and cell size, suggesting that the proteasome function is involved in virulence factor production in C. neoformans (Geddes et al., 2016). Because of the conservative nature of the proteasome function in eukaryotes, there is a legitimate concern about the toxicity of utilizing proteasome inhibitors as potential antifungal drugs. Once identified a potent inhibitor, employing medicinal chemistry to further modify the compound to improve its specificity may increase the feasibility for its further development.

\section{UPS-BASED DRUG DISCOVERY}

With improved understanding of the UPS in regulating protein function and its role in human diseases, it has been realized that inhibitors targeting specific components of the UPS may have significant therapeutic potential (Veggiani et al., 2019). The clinical importance of such components has been demonstrated by the success of the proteasome inhibitors Bortezomib (PS341/ Velcade, approved by the US Food and Drug Administration (FDA) in 2003) and Carfilzomib (PR-171/Kyprolis, approved by the FDA in 2012) in anti-cancer therapy (Richardson et al., 2005; Rentsch et al., 2013). Given the essential role of E1s in globally controlling protein ubiquitination in cells, inhibition of E1s is predicted to be non-specific (Zhang and Sidhu, 2014). It could be feasible to develop E2 inhibitors that selectively target E2-E3 interaction interfaces, with better specificity than targeting the interfaces of E1-E2 and E2-Ub (Zhang and Sidhu, 2014). E3s determine specific substrates for ubiquitination and thus enable selective targeting of a limited number of proteins. Inhibition of E3s may increase the effectiveness of treatment with fewer side effects compared to general UPS inhibitors. Several small molecule inhibitors of E3 ligases have been reported (Zhang and Sidhu, 2014). MDM2 is a RING E3 ligase that regulates the abundance of the tumor suppressor p53 (Reifenberger et al., 1993). Small molecules such as Nutlins and RITA, disrupt the interaction between MDM2 and p53 to mediate p53 ubiquitination and have significant anti-tumor effects (Issaeva et al., 2004). Inhibitors of several SCF family members have also been identified, e.g., CpdA prevents the incorporation of Skp2 into the $\mathrm{SCF}^{\text {skp2 }}$ complex (Chen et al., 2008), while SCF-I2 and SMER3 inhibit Cdc4 and Met30 (Aghajan et al., 2010), respectively. Significant progress has been made to identify inhibitors targeting DUBs because of the substrate specificity and well-defined catalytic pockets in DUBs (Zhang and Sidhu, 2014). Therefore, it is likely feasible to identify small molecules that selectively target specific UPS components.

Several emerging technologies have been developed to manipulate the UPS, aiding drug discovery in this domain (Veggiani et al., 2019). PROTAC (proteolysis-targeting chimeras) technology represents a promising strategy for drug discovery in cancer research (Sakamoto et al., 2001). PROTACs are hetero-bifunctional molecules that recruit an E3 for precise degradation of drug targets (Toure and Crews, 2016), therefore controlling target specificity and reducing systemic toxicity in vivo (Bondeson et al., 2015). Some PROTACs, such as ARV-110 
(an oral protein degradation agent) and ARV-471 (an estrogen receptor (ER) alpha PROTAC molecule), have shown encouraging results in clinical trials (Qi et al., 2021). In yeast, a ligase-trapping system has been developed to aid the identification of E3 ligase targets (Mark et al., 2014; Mark et al., 2016). Although it is not directly utilized for drug discovery, this system will aid the identification of novel E3 substrates, which could be valuable for future drug target discovery. In this system, the E3 is fused with the UBA domain from the ubiquitin receptor proteins $\operatorname{Rad} 23$ or Dsk2. The polyubiquitin-binding domain in the E3 ligase increases the binding affinity to its ubiquitinated substrates, allowing identification of weak and transit substrate proteins. In addition, the commercialization of antibodies that recognize the Lys-€-Gly-Gly (K-€-GG) remnant, which is produced by trypsin digestion of proteins containing ubiquitinated lysine residues, improved the ability to analyze the ubiquitinated substrates and identify ubiquitination sites (Udeshi et al., 2013). Although still understudied and no proven inhibitor against fungal UPS in clinical trial, technologies developed in other systems should provide powerful tools for UPS research in fungal pathogens, and may aid the future drug discovery targeting UPS in fungi.

\section{CONCLUDING REMARKS}

Invasive fungal infections are serious threats to human health with estimated 1.5 million deaths each year (Brown et al., 2012). They are difficult to treat because fungi are eukaryotic cells that share much of their cellular machinery with hosts. The close evolutionary relationship between human and fungi hampers the development of antifungal drugs (Robbins et al., 2016). There is a clear medical need to develop new antifungal drugs. Given that the UPS plays pivotal cellular roles in diverse fungal pathogens and has a track record as a proven drug target in anti-cancer drug

\section{REFERENCES}

Aghajan, M., Jonai, N., Flick, K., Fu, F., Luo, M., Cai, X., et al. (2010). Chemical Genetics Screen for Enhancers of Rapamycin Identifies a Specific Inhibitor of an Scf Family E3 Ubiquitin Ligase. Nat. Biotechnol. 28, 738-742. doi: 10.1038/ nbt.1645

Amerik, A. Y., and Hochstrasser, M. (2004). Mechanism and Function of Deubiquitinating Enzymes. Biochim. Biophys. Acta 1695, 189-207. doi: 10.1016/j.bbamcr.2004.10.003

Atir-Lande, A., Gildor, T., and Kornitzer, D. (2005). Role for the Scfcdc4 Ubiquitin Ligase in Candida Albicans Morphogenesis. Mol. Biol. Cell 16, 2772-2785. doi: 10.1091/mbc.e05-01-0079

Auesukaree, C., Damnernsawad, A., Kruatrachue, M., Pokethitiyook, P., Boonchird, C., Kaneko, Y., et al. (2009). Genome-Wide Identification of Genes Involved in Tolerance to Various Environmental Stresses in Saccharomyces Cerevisiae. J. Appl. Genet. 50, 301-310. doi: 10.1007/ BF03195688

Bachewich, C., and Whiteway, M. (2005). Cyclin Cln3p Links G1 Progression to Hyphal and Pseudohyphal Development in Candida Albicans. Eukaryot. Cell 4, 95-102. doi: 10.1128/EC.4.1.95-102.2005 development, selective targeting of UPS components provides a promising therapeutic strategy to mitigate antifungal resistance and combat fungal infections.

Studies on UPS components in fungal pathogens remains limited and further studies are warranted to better understand the regulation of UPS in fungal development and virulence. Drug development against targets in the fungal UPS has not been explored extensively. Distinguishing UPS proteins in pathogenic fungi from their hosts and selective targeting of the fungal UPS and its fungal function-specific substrates will be crucial steps to develop a UPS inhibitor into a potential antifungal drug. Improved understanding of the specificity of E3s and their downstream substrates in the fungal UPS will increase the feasibility of targeting the UPS as a promising antifungal strategy. UPS substrates that are involved in some unique processes in fungal pathogens, such as cell wall regeneration, morphologic changes, spore germination and certain virulence factors development, are potential antifungal targets. Therefore, research on the fungal UPS system will not only improve our understanding of the molecular basis of UPS regulation of fungal development and pathogenesis, but also may lead to a valuable new avenue of antifungal drug discovery.

\section{AUTHOR CONTRIBUTIONS}

CC and CX designed the review, wrote and edited the manuscript. All authors reviewed and approved the final manuscript. All authors contributed to the article and approved the submitted version.

\section{FUNDING}

This work was supported by the NIH grants R01AI141368, R01AI123315, and R21AI154318 to CX.
Bahram, F., von der Lehr, N., Cetinkaya, C., and Larsson, L. G. (2000). C-Myc Hot Spot Mutations in Lymphomas Result in Inefficient Ubiquitination and Decreased Proteasome-Mediated Turnover. Blood 95, 2104-2110. doi: 10.1182/blood.V95.6.2104

Bensen, E. S., Clemente-Blanco, A., Finley, K. R., Correa-Bordes, J., and Berman, J. (2005). The Mitotic Cyclins Clb2p and Clb4p Affect Morphogenesis in Candida Albicans. Mol. Biol. Cell 16, 3387-3400. doi: 10.1091/mbc.e04-121081

Berleth, E. S., and Pickart, C. M. (1996). Mechanism of Ubiquitin Conjugating Enzyme E2-230k: Catalysis Involving a Thiol Relay? Biochemistry-Us 35, 16641671. doi: 10.1021/bi952105y

Bernassola, F., Karin, M., Ciechanover, A., and Melino, G. (2008). The Hect Family of E3 Ubiquitin Ligases: Multiple Players in Cancer Development. Cancer Cell 14, 10-21. doi: 10.1016/j.ccr.2008.06.001

Biggins, S., Ivanovska, I., and Rose, M. D. (1996). Yeast Ubiquitin-Like Genes Are Involved in Duplication of the Microtubule Organizing Center. J. Cell Biol. 133, 1331-1346. doi: 10.1083/jcb.133.6.1331

Bondeson, D. P., Mares, A., Smith, I. E., Ko, E., Campos, S., Miah, A. H., et al. (2015). Catalytic In Vivo Protein Knockdown by Small-Molecule Protacs. Nat. Chem. Biol. 11, 611-617. doi: 10.1038/nchembio.1858 
Brown, G. D., Denning, D. W., Gow, N. A., Levitz, S. M., Netea, M. G., and White, T. C. (2012). Hidden Killers: Human Fungal Infections. Sci. Transl. Med. 4, 165rv113. doi: 10.1126/scitranslmed.3004404

Butler, D. K., All, O., Goffena, J., Loveless, T., Wilson, T., and Toenjes, K. A. (2006). The Grrl Gene of Candida Albicans Is Involved in the Negative Control of Pseudohyphal Morphogenesis. Fungal Genet. Biol. 43, 573-582. doi: 10.1016/j.fgb.2006.03.004

Celebi, G., Kesim, H., Ozer, E., and Kutlu, O. (2020). The Effect of Dysfunctional Ubiquitin Enzymes in the Pathogenesis of Most Common Diseases. Int. J. Mol. Sci. 21, 6335. doi: 10.3390/ijms21176335

Chapa y Lazo, B., Bates, S., and Sudbery, P. (2005). The G1 Cyclin Cln3 Regulates Morphogenesis in Candida Albicans. Eukaryot. Cell 4, 90-94. doi: 10.1128/ EC.4.1.90-94.2005

Chen, P., Johnson, P., Sommer, T., Jentsch, S., and Hochstrasser, M. (1993). Multiple Ubiquitin-Conjugating Enzymes Participate in the In Vivo Degradation of the Yeast Mat Alpha 2 Repressor. Cell 74, 357-369. doi: 10.1016/0092-8674(93)90426-q

Chen, Q., Li, Y., Wang, J., Li, R., and Chen, B. (2018). Cpubi4 Is Essential for Development and Virulence in Chestnut Blight Fungus. Front. Microbiol. 9, 1286. doi: $10.3389 /$ fmicb.2018.01286

Chen, Q., Xie, W., Kuhn, D. J., Voorhees, P. M., Lopez-Girona, A., Mendy, D., et al. (2008). Targeting the P27 E3 Ligase Scf(Skp2) Results in P27- and Skp2Mediated Cell-Cycle Arrest and Activation of Autophagy. Blood 111, 46904699. doi: 10.1182/blood-2007-09-112904

Chi, Y., Huddleston, M. J., Zhang, X., Young, R. A., Annan, R. S., Carr, S. A., et al. (2001). Negative Regulation of Gen 4 and Msn2 Transcription Factors by Srb 10 Cyclin-Dependent Kinase. Genes Dev. 15, 1078-1092. doi: 10.1101/gad.867501

Chin, C., Lai, W. C., Lee, T. L., Tseng, T. L., and Shieh, J. C. (2013). Dissection of the Candida Albicans Cdc4 Protein Reveals the Involvement of Domains in Morphogenesis and Cell Flocculation. J. BioMed. Sci. 20, 97. doi: 10.1186/14230127-20-97

Chung, E., Cho, C. W., So, H. A., Kang, J. S., Chung, Y. S., and Lee, J. H. (2013). Overexpression of Vrubc1, a Mung Bean E2 Ubiquitin-Conjugating Enzyme, Enhances Osmotic Stress Tolerance in Arabidopsis. PloS One 8, e66056. doi: 10.1371/journal.pone.0066056

Dantuma, N. P., Heinen, C., and Hoogstraten, D. (2009). The Ubiquitin Receptor Rad23: At the Crossroads of Nucleotide Excision Repair and Proteasomal Degradation. DNA Repair (Amst.) 8, 449-460. doi: 10.1016/j.dnarep. 2009.01.005

Das, S., Ramakrishna, S., and Kim, K. S. (2020). Critical Roles of Deubiquitinating Enzymes in the Nervous System and Neurodegenerative Disorders. Mol. Cells 43, 203-214. doi: 10.14348/molcells.2020.2289

Deshaies, R. J., and Joazeiro, C. A. (2009). Ring Domain E3 Ubiquitin Ligases. Annu. Rev. Biochem. 78, 399-434. doi: 10.1146/annurev.biochem.78.101807.093809

Devine, T., and Dai, M. S. (2013). Targeting the Ubiquitin-Mediated Proteasome Degradation of P53 for Cancer Therapy. Curr. Pharm. Des. 19, 3248-3262. doi: 10.2174/1381612811319180009

D’Souza, C. A., Alspaugh, J. A., Yue, C., Harashima, T., Cox, G. M., Perfect, J. R., et al. (2001). Cyclic Amp-Dependent Protein Kinase Controls Virulence of the Fungal Pathogen Cryptococcus Neoformans. Mol. Cell Biol. 21, 3179-3191. doi: 10.1128/MCB.21.9.3179-3191.2001

Duyvesteijn, R. G., van Wijk, R., Boer, Y., Rep, M., Cornelissen, B. J., and Haring, M. A. (2005). Frp1 Is a Fusarium Oxysporum F-Box Protein Required for Pathogenicity on Tomato. Mol. Microbiol. 57, 1051-1063. doi: 10.1111/j.13652958.2005.04751.x

Elsasser, S., and Finley, D. (2005). Delivery of Ubiquitinated Substrates to ProteinUnfolding Machines. Nat. Cell Biol. 7, 742-749. doi: 10.1038/ncb0805-742

Enenkel, C. (2014). Proteasome Dynamics. Biochim. Biophys. Acta 1843, 39-46. doi: 10.1016/j.bbamcr.2013.03.023

Fang, W., Price, M. S., Toffaletti, D. L., Tenor, J., Betancourt-Quiroz, M., Price, J. L., et al. (2012). Pleiotropic Effects of Deubiquitinating Enzyme Ubp5 on Growth and Pathogenesis of Cryptococcus Neoformans. PloS One 7, e38326. doi: 10.1371/journal.pone.0038326

Fan, C. L., and Liu, T. B. (2021). The Vacuolar Morphogenesis Protein Vam6-Like Protein Vlp1 Is Required for Pathogenicity of Cryptococcus Neoformans. J. Fungi (Basel) 7, 418. doi: 10.3390/jof7060418

Farmer, L. M., Book, A. J., Lee, K. H., Lin, Y. L., Fu, H., and Vierstra, R. D. (2010). The Rad23 Family Provides an Essential Connection Between the 26s
Proteasome and Ubiquitylated Proteins in Arabidopsis. Plant Cell 22, 124142. doi: $10.1105 /$ tpc. 109.072660

Feldman, R. M., Correll, C. C., Kaplan, K. B., and Deshaies, R. J. (1997). A Complex of Cdc4p, Skplp, and Cdc53p/Cullin Catalyzes Ubiquitination of the Phosphorylated Cdk Inhibitor Siclp. Cell 91, 221-230. doi: 10.1016/s00928674(00)80404-3

Feng, J., Yao, S., Dong, Y., Hu, J., Whiteway, M., and Feng, J. (2020). ). Nucleotide Excision Repair Protein Rad23 Regulates Cell Virulence Independent of Rad4 in Candida albicans. mSphere 5, e00062-20. doi: 10.1128/mSphere.00062-20

Feussner, K., Feussner, I., Leopold, I., and Wasternack, C. (1997). Isolation of a Cdna Coding for an Ubiquitin-Conjugating Enzyme Ubcl of Tomato-the First Stress-Induced Ubc of Higher Plants. FEBS Lett. 409, 211-215. doi: 10.1016/ s0014-5793(97)00509-7

Finley, D. (2009). Recognition and Processing of Ubiquitin-Protein Conjugates by the Proteasome. Annu. Rev. Biochem. 78, 477-513. doi: 10.1146/ annurev.biochem.78.081507.101607

Finley, D., Ozkaynak, E., and Varshavsky, A. (1987). The Yeast Polyubiquitin Gene Is Essential for Resistance to High Temperatures, Starvation, and Other Stresses. Cell 48, 1035-1046. doi: 10.1016/0092-8674(87)90711-2

Finley, D., Ulrich, H. D., Sommer, T., and Kaiser, P. (2012). The UbiquitinProteasome System of Saccharomyces Cerevisiae. Genetics 192, 319-360. doi: 10.1534/genetics.112.140467

Flick, K. M., Spielewoy, N., Kalashnikova, T. I., Guaderrama, M., Zhu, Q., Chang, H. C., et al. (2003). Grr1-Dependent Inactivation of Mth1 Mediates GlucoseInduced Dissociation of Rgt1 From Hxt Gene Promoters. Mol. Biol. Cell 14, 3230-3241. doi: 10.1091/mbc.e03-03-0135

Fraser, J., Luu, H. A., Neculcea, J., Thomas, D. Y., and Storms, R. K. (1991). Ubiquitin Gene Expression: Response to Environmental Changes. Curr. Genet. 20, 17-23. doi: 10.1007/BF00312760

Frawley, D., and Bayram, O. (2020). Identification of Skpa-Cula-F-Box E3 Ligase Complexes in Pathogenic Aspergilli. Fungal Genet. Biol. 140:103396. doi: 10.1016/j.fgb.2020.103396

Geddes, J. M., Caza, M., Croll, D., Stoynov, N., Foster, L. J., and Kronstad, J. W. (2016). Analysis of the Protein Kinase a-Regulated Proteome of Cryptococcus Neoformans Identifies a Role for the Ubiquitin-Proteasome Pathway in Capsule Formation. Mbio 7, e01862-e01815. doi: 10.1128/mBio.01862-15

Ghaboosi, N., and Deshaies, R. J. (2007). A Conditional Yeast E1 Mutant Blocks the Ubiquitin-Proteasome Pathway and Reveals a Role for Ubiquitin Conjugates in Targeting Rad23 to the Proteasome. Mol. Biol. Cell 18, 19531963. doi: 10.1091/mbc.e06-10-0965

Glickman, M. H., and Ciechanover, A. (2002). The Ubiquitin-Proteasome Proteolytic Pathway: Destruction for the Sake of Construction. Physiol. Rev. 82, 373-428. doi: 10.1152/physrev.00027.2001

Goto, J., Otaki, Y., Watanabe, T., and Watanabe, M. (2021). The Role of Hect-Type E3 Ligase in the Development of Cardiac Disease. Int. J. Mol. Sci. 22, 6065. doi: $10.3390 /$ ijms 22116065

Guo, M., Gao, F., Zhu, X., Nie, X., Pan, Y., and Gao, Z. (2015). Mogrr1, a Novel FBox Protein, Is Involved in Conidiogenesis and Cell Wall Integrity and Is Critical for the Full Virulence of Magnaporthe Oryzae. Appl. Microbiol. Biotechnol. 99, 8075-8088. doi: 10.1007/s00253-015-6820-x

Gupta, A., Behl, T., Aleya, L., Rahman, M. H., Yadav, H. N., Pal, G., et al. (2021). Role of Upp Pathway in Amelioration of Diabetes-Associated Complications. Environ. Sci. Pollut. Res. Int. 28, 19601-19614. doi: 10.1007/s11356-021-12781-5

Han, Y. K., Kim, M. D., Lee, S. H., Yun, S. H., and Lee, Y. W. (2007). A Novel FBox Protein Involved in Sexual Development and Pathogenesis in Gibberella Zeae. Mol. Microbiol. 63, 768-779. doi: 10.1111/j.1365-2958.2006.05557.x

Han, L. T., Wu, L., and Liu, T. B. (2020). A Predicted Mannoprotein Cmp1 Regulates Fungal Virulence in Cryptococcus Neoformans. Pathogens 9, 881. doi: $10.3390 /$ pathogens 9110881

Heideker, J., and Wertz, I. E. (2015). Dubs, the Regulation of Cell Identity and Disease. Biochem. J. 467:191. doi: 10.1042/bj4670191

Hershko, A., and Ciechanover, A. (1998). The Ubiquitin System. Annu. Rev. Biochem. 67, 425-479. doi: 10.1146/annurev.biochem.67.1.425

He, M., Zhou, Z., Shah, A. A., Zou, H., Tao, J., Chen, Q., et al. (2016). The Emerging Role of Deubiquitinating Enzymes in Genomic Integrity, Diseases, and Therapeutics. Cell Biosci. 6, 62. doi: 10.1186/s13578-016-0127-1

Hicke, L. (2001). Protein Regulation by Monoubiquitin. Nat. Rev. Mol. Cell Biol. 2, 195-201. doi: 10.1038/35056583 
Hicke, L., and Dunn, R. (2003). Regulation of Membrane Protein Transport by Ubiquitin and Ubiquitin-Binding Proteins. Annu. Rev. Cell Dev. Biol. 19, 141172. doi: 10.1146/annurev.cellbio.19.110701.154617

Hossain, S., Veri, A. O., and Cowen, L. E. (2020). The Proteasome Governs Fungal Morphogenesis Via Functional Connections With Hsp90 and cAMP-Protein Kinase a Signaling. Mbio 11, e00290-20. doi: 10.1128/mBio.00290-20

Hosseini, S. M., Okoye, I., Chaleshtari, M. G., Hazhirkarzar, B., Mohamadnejad, J., Azizi, G., et al. (2019). E2 Ubiquitin-Conjugating Enzymes in Cancer: Implications for Immunotherapeutic Interventions. Clin. Chim. Acta 498, 126-134. doi: 10.1016/j.cca.2019.08.020

Huang, G. (2012). Regulation of Phenotypic Transitions in the Fungal Pathogen Candida Albicans. Virulence 3, 251-261. doi: 10.4161/viru.20010

Huang, H., Kahana, A., Gottschling, D. E., Prakash, L., and Liebman, S. W. (1997). The Ubiquitin-Conjugating Enzyme Rad6 (Ubc2) Is Required for Silencing in Saccharomyces Cerevisiae. Mol. Cell Biol. 17, 6693-6699. doi: 10.1128/ MCB.17.11.6693

Huang, X. L., Zhang, L., Duan, Y., Wang, Y. J., Zhao, J. H., and Wang, J. (2016). E3 Ubiquitin Ligase: A Potential Regulator in Fibrosis and Systemic Sclerosis. Cell Immunol. 306-307, 1-8. doi: 10.1016/j.cellimm.2016.07.003

Huibregtse, J. M., Scheffner, M., Beaudenon, S., and Howley, P. M. (1995). A Family of Proteins Structurally and Functionally Related to the E6-Ap Ubiquitin-Protein Ligase. Proc. Natl. Acad. Sci. U.S.A. 92, 5249. doi: 10.1073/ pnas.92.11.5249-a

Issaeva, N., Bozko, P., Enge, M., Protopopova, M., Verhoef, L. G., Masucci, M., et al. (2004). Small Molecule Rita Binds to P53, Blocks P53-Hdm-2 Interaction and Activates P53 Function in Tumors. Nat. Med. 10, 1321-1328. doi: 10.1038/nm1146

Jelinsky, S. A., Estep, P., Church, G. M., and Samson, L. D. (2000). Regulatory Networks Revealed by Transcriptional Profiling of Damaged Saccharomyces Cerevisiae Cells: Rpn4 Links Base Excision Repair With Proteasomes. Mol. Cell Biol. 20, 8157-8167. doi: 10.1128/MCB.20.21.8157-8167.2000

Jeon, E. H., Pak, J. H., Kim, M. J., Kim, H. J., Shin, S. H., Lee, J. H., et al. (2012). Ectopic Expression of Ubiquitin-Conjugating Enzyme Gene From Wild Rice, Ogubc1, Confers Resistance Against Uv-B Radiation and Botrytis Infection in Arabidopsis Thaliana. Biochem. Biophys. Res. Commun. 427, 309-314. doi: 10.1016/j.bbrc.2012.09.048

Johnk, B., Bayram, O., Abelmann, A., Heinekamp, T., Mattern, D. J., Brakhage, A. A., et al. (2016). Scf Ubiquitin Ligase F-Box Protein Fbx15 Controls Nuclear Co-Repressor Localization, Stress Response and Virulence of the Human Pathogen Aspergillus Fumigatus. PloS Pathog. 12, e1005899. doi: 10.1371/ journal.ppat.1005899

Johnson, M. D. (2021). Antifungals in Clinical Use and the Pipeline. Infect. Dis. Clin. North Am. 35, 341-371. doi: 10.1016/j.idc.2021.03.005

Jonkers, W., JA, V. A. N. K., Tijm, P., Lee, Y. W., Tudzynski, P., Rep, M., et al. (2011). The Frp1 F-Box Gene Has Different Functions in Sexuality, Pathogenicity and Metabolism in Three Fungal Pathogens. Mol. Plant Pathol. 12, 548-563. doi: 10.1111/j.1364-3703.2010.00689.x

Kee, Y., and Huang, T. T. (2016). Role of Deubiquitinating Enzymes in DNA Repair. Mol. Cell Biol. 36, 524-544. doi: 10.1128/MCB.00847-15

Kingsbury, J. M., and McCusker, J. H. (2010a). Fungal Homoserine Kinase (Thrldelta) Mutants Are Attenuated in Virulence and Die Rapidly Upon Threonine Starvation and Serum Incubation. Eukaryot. Cell 9, 729-737. doi: 10.1128/EC.00045-10

Kingsbury, J. M., and McCusker, J. H. (2010b). Homoserine Toxicity in Saccharomyces Cerevisiae and Candida Albicans Homoserine Kinase (Thrldelta) Mutants. Eukaryot. Cell 9, 717-728. doi: 10.1128/EC.00044-10

Komander, D. (2009). The Emerging Complexity of Protein Ubiquitination. Biochem. Soc. Trans. 37, 937-953. doi: 10.1042/BST0370937

Komander, D., Clague, M. J., and Urbe, S. (2009). Breaking the Chains: Structure and Function of the Deubiquitinases. Nat. Rev. Mol. Cell Biol. 10, 550-563. doi: $10.1038 / \mathrm{nrm} 2731$

Komander, D., and Rape, M. (2012). The Ubiquitin Code. Annu. Rev. Biochem. 81, 203-229. doi: 10.1146/annurev-biochem-060310-170328

Kraft, E., Stone, S. L., Ma, L., Su, N., Gao, Y., Lau, O. S., et al. (2005). Genome Analysis and Functional Characterization of the E2 and Ring-Type E3 Ligase Ubiquitination Enzymes of Arabidopsis. Plant Physiol. 139, 1597-1611. doi: 10.1104/pp.105.067983

Kravtsova-Ivantsiv, Y., Cohen, S., and Ciechanover, A. (2009). Modification by Single Ubiquitin Moieties Rather Than Polyubiquitination Is Sufficient for
Proteasomal Processing of the P105 Nf-Kappab Precursor. Mol. Cell 33, 496504. doi: 10.1016/j.molcel.2009.01.023

Kulkarni, M., and Smith, H. E. (2008). E1 Ubiquitin-Activating Enzyme Uba-1 Plays Multiple Roles Throughout C. Elegans Development. PloS Genet. 4, e1000131. doi: 10.1371/journal.pgen.1000131

Lahari, T., Lazaro, J., and Schroeder, D. F. (2017). Rad4 and Rad23/Hmr Contribute to Arabidopsis UV Tolerance. Genes (Basel) 9, 8. doi: 10.3390/ genes 9010008

Leach, M. D., Stead, D. A., Argo, E., MacCallum, D. M., and Brown, A. J. (2011). Molecular and Proteomic Analyses Highlight the Importance of Ubiquitination for the Stress Resistance, Metabolic Adaptation, Morphogenetic Regulation and Virulence of Candida Albicans. Mol. Microbiol. 79, 1574-1593. doi: 10.1111/j.1365-2958.2011.07542.x

Lee, Y. T., Fang, Y. Y., Sun, Y. W., Hsu, H. C., Weng, S. M., Tseng, T. L., et al. (2018). Thrl Mediates Gcn4 and Cdc4 to Link Morphogenesis With Nutrient Sensing and the Stress Response in Candida Albicans. Int. J. Mol. Med. 42, 3193-3208. doi: 10.3892/ijmm.2018.3930

Lee, D. H., and Goldberg, A. L. (1998). Proteasome Inhibitors: Valuable New Tools for Cell Biologists. Trends Cell Biol. 8, 397-403. doi: 10.1016/s0962-8924(98) 01346-4

Leng, P., Sudbery, P. E., and Brown, A. J. (2000). Rad6p Represses Yeast-Hypha Morphogenesis in the Human Fungal Pathogen Candida Albicans. Mol. Microbiol. 35, 1264-1275. doi: 10.1046/j.1365-2958.2000.01801.x

Li, G., Qi, X., Sun, G., Rocha, R. O., Segal, L. M., Downey, K. S., et al. (2020). Terminating Rice Innate Immunity Induction Requires a Network of Antagonistic and Redox-Responsive E3 Ubiquitin Ligases Targeting a Fungal Sirtuin. New Phytol. 226, 523-540. doi: 10.1111/nph.16365

Liu, O. W., Chun, C. D., Chow, E. D., Chen, C., Madhani, H. D., and Noble, S. M. (2008). Systematic Genetic Analysis of Virulence in the Human Fungal Pathogen Cryptococcus Neoformans. Cell 135, 174-188. doi: 10.1016/ j.cell.2008.07.046

Liu, Y., Dai, H., and Xiao, W. (1997). Uas(Mag1), a Yeast Cis-Acting Element That Regulates the Expression of Mag1, Is Located Within the Protein Coding Region of Ddil. Mol. Gen. Genet. 255, 533-542. doi: 10.1007/s004380050526

Liu, J., Shaik, S., Dai, X., Wu, Q., Zhou, X., Wang, Z., et al. (2015). Targeting the Ubiquitin Pathway for Cancer Treatment. Biochim. Biophys. Acta 1855, 50-60. doi: 10.1016/j.bbcan.2014.11.005

Liu, K. H., and Shen, W. C. (2011). Mating Differentiation in Cryptococcus Neoformans Is Negatively Regulated by the Crk1 Protein Kinase. Fungal Genet. Biol. 48, 225-240. doi: 10.1016/j.fgb.2010.11.005

Liu, W., Tang, X., Qi, X., Fu, X., Ghimire, S., Ma, R., et al. (2020). The Ubiquitin Conjugating Enzyme: An Important Ubiquitin Transfer Platform in UbiquitinProteasome System. Int. J. Mol. Sci. 21, 2894. doi: 10.3390/ijms21082894

Liu, T. B., Wang, Y., Stukes, S., Chen, Q., Casadevall, A., and Xue, C. (2011). The FBox Protein Fbp1 Regulates Sexual Reproduction and Virulence in Cryptococcus Neoformans. Eukaryot. Cell 10, 791-802. doi: 10.1128/EC.00004-11

Liu, T. B., and Xue, C. (2011). The Ubiquitin-Proteasome System and F-Box Proteins in Pathogenic Fungi. Mycobiology 39, 243-248. doi: 10.5941/ MYCO.2011.39.4.243

Liu, T. B., and Xue, C. (2014). Fbp1-Mediated Ubiquitin-Proteasome Pathway Controls Cryptococcus Neoformans Virulence by Regulating Fungal Intracellular Growth in Macrophages. Infect. Immun. 82, 557-568. doi: 10.1128/IAI.00994-13

Li, W. J., Wang, Y. M., Zheng, X. D., Shi, Q. M., Zhang, T. T., Bai, C., et al. (2006), The F-Box Protein Grr1 Regulates the Stability of Ccn1, Cln3 and Hof1 and Cell Morphogenesis in Candida Albicans. Mol. Microbiol. 62, 212-226. doi: $10.1111 / j .1365-2958.2006 .05361 . x$

Li, S., Zhao, J., Shang, D., Kass, D. J., and Zhao, Y. (2018). Ubiquitination and Deubiquitination Emerge as Players in Idiopathic Pulmonary Fibrosis Pathogenesis and Treatment. JCI Insight 3, e120362.. doi: 10.1172/jci.insight.120362

Mao, X., Sethi, G., Zhang, Z., and Wang, Q. (2018). The Emerging Roles of the Herc Ubiquitin Ligases in Cancer. Curr. Pharm. Des. 24, 1676-1681. doi: 10.2174/1381612824666180528081024

Mark, K. G., Loveless, T. B., and Toczyski, D. P. (2016). Isolation of Ubiquitinated Substrates by Tandem Affinity Purification of E3 Ligase-Polyubiquitin-Binding Domain Fusions (Ligase Traps). Nat. Protoc. 11, 291-301. doi: 10.1038/ nprot.2016.008

Mark, K. G., Simonetta, M., Maiolica, A., Seller, C. A., and Toczyski, D. P. (2014). Ubiquitin Ligase Trapping Identifies an Scf(Saf1) Pathway Targeting 
Unprocessed Vacuolar/Lysosomal Proteins. Mol. Cell 53, 148-161. doi: 10.1016/j.molcel.2013.12.003

Masso-Silva, J., Espinosa, V., Liu, T. B., Wang, Y., Xue, C., and Rivera, A. (2018). The F-Box Protein Fbp1 Shapes the Immunogenic Potential of Cryptococcus Neoformans. Mbio 9, e01828-17. doi: 10.1128/mBio.01828-17

Mat Nanyan, N. S. B., Watanabe, D., Sugimoto, Y., and Takagi, H. (2020). Effect of the Deubiquitination Enzyme Gene Ubp6 on the Stress-Responsive Transcription Factor Msn2-Mediated Control of the Amino Acid Permease Gnp1 in Yeast. J. Biosci. Bioeng 129, 423-427. doi: 10.1016/j.jbiosc.2019.10.002

McGrath, J. P., Jentsch, S., and Varshavsky, A. (1991). Uba1: An Essential Yeast Gene Encoding Ubiquitin-Activating Enzyme. EMBO J. 10, 227-236. doi: 10.1002/j.1460-2075.1991.tb07940.x

Meimoun, A., Holtzman, T., Weissman, Z., McBride, H. J., Stillman, D. J., Fink, G. R., et al. (2000). Degradation of the Transcription Factor Gcn4 Requires the Kinase Pho85 and the Scf(Cdc4) Ubiquitin-Ligase Complex. Mol. Biol. Cell 11, 915-927. doi: 10.1091/mbc.11.3.915

Mendelsohn, S., Pinsky, M., Weissman, Z., and Kornitzer, D. (2017). Regulation of the Candida Albicans Hypha-Inducing Transcription Factor Ume6 by the Cdk1 Cyclins Cln3 and Hgcl. mSphere 2, e00248-16. doi: 10.1128/mSphere.00248-16

Miller, R. A., and Britigan, B. E. (1997). Role of Oxidants in Microbial Pathophysiology. Clin. Microbiol. Rev. 10, 1-18. doi: 10.1128/CMR.10.1.1

Millyard, L., Lee, J., Zhang, C., Yates, G., and Sadanandom, A. (2016). The Ubiquitin Conjugating Enzyme, Tau4 Regulates Wheat Defence Against the Phytopathogen Zymoseptoria Tritici. Sci. Rep. 6:35683. doi: 10.1038/srep35683

Mitchell, T. G., and Perfect, J. R. (1995). Cryptococcosis in the Era of Aids-100 Years After the Discovery of Cryptococcus Neoformans. Clin. Microbiol. Rev. 8, 515-548. doi: 10.1128/CMR.8.4.515

Nanduri, B., Suvarnapunya, A. E., Venkatesan, M., and Edelmann, M. J. (2013). Deubiquitinating Enzymes as Promising Drug Targets for Infectious Diseases. Curr. Pharm. Des. 19, 3234-3247. doi: 10.2174/1381612811319180008

Nunes, A. T., and Annunziata, C. M. (2017). Proteasome Inhibitors: Structure and Function. Semin. Oncol. 44, 377-380. doi: 10.1053/j.seminoncol.2018.01.004

Oh, Y., Franck, W. L., Han, S. O., Shows, A., Gokce, E., Muddiman, D. C., et al. (2012). Polyubiquitin Is Required for Growth, Development and Pathogenicity in the Rice Blast Fungus Magnaporthe Oryzae. PloS One 7, e42868. doi: 10.1371/journal.pone.0042868

Ozkaynak, E., Finley, D., Solomon, M. J., and Varshavsky, A. (1987). The Yeast Ubiquitin Genes: A Family of Natural Gene Fusions. EMBO J. 6, 1429-1439. doi: 10.1002/j.1460-2075.1987.tb02384.x

Pan, Z. Q. (2020). Cullin-Ring E3 Ubiquitin Ligase 7 in Growth Control and Cancer. Adv. Exp. Med. Biol. 1217, 285-296. doi: 10.1007/978-981-15-1025$0 \_17$

Peng, J., Schwartz, D., Elias, J. E., Thoreen, C. C., Cheng, D., Marsischky, G., et al. (2003). A Proteomics Approach to Understanding Protein Ubiquitination. Nat. Biotechnol. 21, 921-926. doi: 10.1038/nbt849

Pesin, J. A., and Orr-Weaver, T. L. (2008). Regulation of Apc/C Activators in Mitosis and Meiosis. Annu. Rev. Cell Dev. Biol. 24, 475-499. doi: 10.1146/ annurev.cellbio.041408.115949

Pickart, C. M. (2001). Mechanisms Underlying Ubiquitination. Annu. Rev. Biochem. 70, 503-533. doi: 10.1146/annurev.biochem.70.1.503

Popovic, D., Vucic, D., and Dikic, I. (2014). Ubiquitination in Disease Pathogenesis and Treatment. Nat. Med. 20, 1242-1253. doi: 10.1038/nm.3739

Qi, S. M., Dong, J., Xu, Z. Y., Cheng, X. D., Zhang, W. D., and Qin, J. J. (2021). Protac: An Effective Targeted Protein Degradation Strategy for Cancer Therapy. Front. Pharmacol. 12:692574. doi: 10.3389/fphar.2021.692574

Que, Y., Xu, Z., Wang, C., Lv, W., Yue, X., Xu, L., et al. (2020). The Putative Deubiquitinating Enzyme Moubp4 Is Required for Infection-Related Morphogenesis and Pathogenicity in the Rice Blast Fungus Magnaporthe Oryzae. Curr. Genet. 66, 561-576. doi: 10.1007/s00294-019-01049-8

Reifenberger, G., Liu, L., Ichimura, K., Schmidt, E. E., and Collins, V. P. (1993). Amplification and Overexpression of the $M d m 2$ Gene in a Subset of Human Malignant Gliomas Without P53 Mutations. Cancer Res. 53, 2736-2739.

Rentsch, A., Landsberg, D., Brodmann, T., Bulow, L., Girbig, A. K., and Kalesse, M. (2013). Synthesis and Pharmacology of Proteasome Inhibitors. Angew. Chem. Int. Ed. Engl. 52, 5450-5488. doi: 10.1002/anie.201207900

Reyes-Turcu, F. E., Ventii, K. H., and Wilkinson, K. D. (2009). Regulation and Cellular Roles of Ubiquitin-Specific Deubiquitinating Enzymes. Annu. Rev. Biochem. 78, 363-397. doi: 10.1146/annurev.biochem.78.082307.091526
Richardson, P. G., Sonneveld, P., Schuster, M. W., Irwin, D., Stadtmauer, E. A., Facon, T., et al. (2005). Bortezomib or High-Dose Dexamethasone for Relapsed Multiple Myeloma. N. Engl. J. Med. 352, 2487-2498. doi: 10.1056/NEJMoa043445

Robbins, N., Wright, G. D., and Cowen, L. E. (2016). Antifungal Drugs: The Current Armamentarium and Development of New Agents. Microbiol. Spectr. 4 (5), FUNK-0002-2016. doi: 10.1128/microbiolspec.FUNK-0002-2016

Rodrigues, M. L., and Nosanchuk, J. D. (2020). Fungal Diseases as Neglected Pathogens: A Wake-Up Call to Public Health Officials. PloS Negl. Trop. Dis. 14, e0007964. doi: 10.1371/journal.pntd.0007964

Roig, P., and Gozalbo, D. (2002). The Candida Albicans Ubi3 Gene Encoding a Hybrid Ubiquitin Fusion Protein Involved in Ribosome Biogenesis Is Essential for Growth. FEMS Yeast Res. 2, 25-30. doi: 10.1111/j.1567-1364. 2002.tb00065.x

Roig, P., and Gozalbo, D. (2003). Depletion of Polyubiquitin Encoded by the Ubi4 Gene Confers Pleiotropic Phenotype to Candida Albicans Cells. Fungal Genet. Biol. 39, 70-81. doi: 10.1016/s1087-1845(03)00004-5

Roig, P., Martinez, J. P., Gil, M. L., and Gozalbo, D. (2000). Molecular Cloning and Characterization of the Candida Albicans Ubi3 Gene Coding for a UbiquitinHybrid Protein. Yeast 16, 1413-1419. doi: 10.1002/1097-0061(200011) 16:15<1413::AID-YEA632>3.0.CO;2-U

Rotin, D., and Kumar, S. (2009). Physiological Functions of the Hect Family of Ubiquitin Ligases. Nat. Rev. Mol. Cell Biol. 10, 398-409. doi: 10.1038/nrm2690

Sakamoto, K. M., Kim, K. B., Kumagai, A., Mercurio, F., Crews, C. M., and Deshaies, R. J. (2001). Protacs: Chimeric Molecules That Target Proteins to the Skp1-Cullin-F Box Complex for Ubiquitination and Degradation. Proc. Natl. Acad. Sci. U.S.A. 98, 8554-8559. doi: 10.1073/pnas.141230798

Sela, N., Atir-Lande, A., and Kornitzer, D. (2012). Neddylation and Cand1 Independently Stimulate Scf Ubiquitin Ligase Activity in Candida Albicans. Eukaryot. Cell 11, 42-52. doi: 10.1128/EC.05250-11

Senft, D., Qi, J., and Ronai, Z. A. (2018). Ubiquitin Ligases in Oncogenic Transformation and Cancer Therapy. Nat. Rev. Cancer 18, 69-88. doi: 10.1038/nrc.2017.105

Seol, J. H., Feldman, R. M., Zachariae, W., Shevchenko, A., Correll, C. C., Lyapina, S., et al. (1999). Cdc53/Cullin and the Essential Hrt1 Ring-H2 Subunit of Scf Define a Ubiquitin Ligase Module That Activates the E2 Enzyme Cdc34. Genes Dev. 13, 1614-1626. doi: 10.1101/gad.13.12.1614

Sepulveda, P., Cervera, A. M., Lopez-Ribot, J. L., Chaffin, W. L., Martinez, J. P., and Gozalbo, D. (1996). Cloning and Characterization of a Cdna Coding for Candida Albicans Polyubiquitin. J. Med. Vet. Mycol. 34, 315-322. doi: $10.1080 / 02681219680000541$

Sherman, D. J., and Li, J. (2020). Proteasome Inhibitors: Harnessing Proteostasis to Combat Disease. Molecules 25, 671. doi: 10.3390/molecules25030671

Shi, H. B., Chen, G. Q., Chen, Y. P., Dong, B., Lu, J. P., Liu, X. H., et al. (2016). Morad6-Mediated Ubiquitination Pathways Are Essential for Development and Pathogenicity in Magnaporthe Oryzae. Environ. Microbiol. 18, 4170-4187. doi: 10.1111/1462-2920.13515

Shi, H. B., Chen, N., Zhu, X. M., Liang, S., Li, L., Wang, J. Y., et al. (2019). F-Box Proteins Mofwd1, Mocdc4 and Mofbx15 Regulate Development and Pathogenicity in the Rice Blast Fungus Magnaporthe Oryzae. Environ. Microbiol. 21, 3027-3045. doi: 10.1111/1462-2920.14699

Shieh, J. C., White, A., Cheng, Y. C., and Rosamond, J. (2005). Identification and Functional Characterization of Candida Albicans Cdc4. J. BioMed. Sci. 12, $913-$ 924. doi: 10.1007/s11373-005-9027-9

Skowyra, D., Craig, K. L., Tyers, M., Elledge, S. J., and Harper, J. W. (1997). F-Box Proteins Are Receptors That Recruit Phosphorylated Substrates to the Scf Ubiquitin-Ligase Complex. Cell 91, 209-219. doi: 10.1016/s0092-8674(00)80403-1

Skowyra, D., Koepp, D. M., Kamura, T., Conrad, M. N., Conaway, R. C., Conaway, J. W., et al. (1999). Reconstitution of G1 Cyclin Ubiquitination With Complexes Containing Scfgrr1 and Rbx1. Science 284, 662-665. doi: $10.1126 /$ science.284.5414.662

Slingerland, J., and Pagano, M. (2000). Regulation of the Cdk Inhibitor P27 and Its Deregulation in Cancer. J. Cell Physiol. 183, 10-17. doi: 10.1002/(SICI)10974652(200004)183:1<10::AID-JCP2>3.0.CO;2-I

Spitzer, E. D., and Spitzer, S. G. (1995). Structure of the Ubiquitin-Encoding Genes of Cryptococcus Neoformans. Gene 161, 113-117. doi: 10.1016/0378-1119(95) 00231-t

Sweigard, J. A., Carroll, A. M., Farrall, L., Chumley, F. G., and Valent, B. (1998). Magnaporthe Grisea Pathogenicity Genes Obtained Through Insertional 
Mutagenesis. Mol. Plant-Microbe Interact.: MPMI 11, 404-412. doi: 10.1094/ MPMI.1998.11.5.404

Toure, M., and Crews, C. M. (2016). Small-Molecule Protacs: New Approaches to Protein Degradation. Angew. Chem. Int. Ed. Engl. 55, 1966-1973. doi: 10.1002/ anie. 201507978

Trunk, K., Gendron, P., Nantel, A., Lemieux, S., Roemer, T., and Raymond, M. (2009). Depletion of the Cullin Cdc53p Induces Morphogenetic Changes in Candida Albicans. Eukaryot. Cell 8, 756-767. doi: 10.1128/EC.00332-08

Tseng, T. L., Lai, W. C., Jian, T., Li, C., Sun, H. F., Way, T. D., et al. (2010). Affinity Purification of Candida Albicans Cacdc4-Associated Proteins Reveals the Presence of Novel Proteins Involved in Morphogenesis. Biochem. Biophys. Res. Commun. 395, 152-157. doi: 10.1016/j.bbrc.2010.03.162

Tseng, T. L., Lai, W. C., Lee, T. L., Hsu, W. H., Sun, Y. W., Li, W. C., et al. (2015). A Role of Candida Albicans Cdc4 in the Negative Regulation of Biofilm Formation. Can. J. Microbiol. 61, 247-255. doi: 10.1139/cjm-2014-0526

Udeshi, N. D., Mertins, P., Svinkina, T., and Carr, S. A. (2013). Large-Scale Identification of Ubiquitination Sites by Mass Spectrometry. Nat. Protoc. 8, 1950-1960. doi: 10.1038/nprot.2013.120

van Wijk, S. J., and Timmers, H. T. (2010). The Family of Ubiquitin-Conjugating Enzymes (E2s): Deciding Between Life and Death of Proteins. FASEB J. 24, 981-993. doi: 10.1096/fj.09-136259

Veggiani, G., Gerpe, M. C. R., Sidhu, S. S., and Zhang, W. (2019). Emerging Drug Development Technologies Targeting Ubiquitination for Cancer Therapeutics. Pharmacol. Ther. 199, 139-154. doi: 10.1016/j.pharmthera.2019.03.003

Verma, R., Oania, R., Graumann, J., and Deshaies, R. J. (2004). Multiubiquitin Chain Receptors Define a Layer of Substrate Selectivity in the UbiquitinProteasome System. Cell 118, 99-110. doi: 10.1016/j.cell.2004.06.014

Verma, S., Shakya, V. P. S., and Idnurm, A. (2019). The Dual Function Gene Rad23 Contributes to Cryptococcus Neoformans Virulence Independently of Its Role in Nucleotide Excision DNA Repair. Gene 717:144043. doi: 10.1016/ j.gene.2019.144043

Wang, Y., Argiles-Castillo, D., Kane, E. I., Zhou, A., and Spratt, D. E. (2020). Hect E3 Ubiquitin Ligases - Emerging Insights Into Their Biological Roles and Disease Relevance. J. Cell Sci. 133, jcs228072. doi: 10.1242/jcs.228072

Wang, Z., Kang, W., You, Y., Pang, J., Ren, H., Suo, Z., et al. (2019a). Usp7: Novel Drug Target in Cancer Therapy. Front. Pharmacol. 10, 427. doi: 10.3389/ fphar.2019.00427

Wang, D. Y., Ren, K., Tong, S. M., Ying, S. H., and Feng, M. G. (2020). Pleiotropic Effects of Ubi4, a Polyubiquitin Precursor Required for Ubiquitin Accumulation, Conidiation and Pathogenicity of a Fungal Insect Pathogen. Environ. Microbiol. 22, 2564-2580. doi: 10.1111/1462-2920.14940

Wang, Y., Wang, K., Masso-Silva, J. A., Rivera, A., and Xue, C. (2019). A HeatKilled Cryptococcus Mutant Strain Induces Host Protection Against Multiple Invasive Mycoses in a Murine Vaccine Model. Mbio 10, e2145-19. doi: $10.1128 / \mathrm{mBio} .02145-19$

Wang, Z., Zhang, H., Liu, C., Xing, J., and Chen, X. L. (2018). A Deubiquitinating Enzyme Ubp14 Is Required for Development, Stress Response, Nutrient Utilization, and Pathogenesis of Magnaporthe Oryzae. Front. Microbiol. 9:769. doi: 10.3389/fmicb.2018.00769

Wang, Z., Zhu, H., Cheng, Y., Jiang, Y., Li, Y., and Huang, B. (2019b). The Polyubiquitin Gene Mrubi4 Is Required for Conidiation, Conidial Germination, and Stress Tolerance in the Filamentous Fungus Metarhizium Robertsii. Genes (Basel) 10, 412. doi: 10.3390/genes10060412

Watts, R. J., Hoopfer, E. D., and Luo, L. (2003). Axon Pruning During Drosophila Metamorphosis: Evidence for Local Degeneration and Requirement of the Ubiquitin-Proteasome System. Neuron 38, 871-885. doi: 10.1016/s0896-6273 (03)00295-2

Wenzel, D. M., and Klevit, R. E. (2012). Following Ariadne's Thread: A New Perspective on Rbr Ubiquitin Ligases. BMC Biol. 10:24. doi: 10.1186/1741-7007-10-24

Wenzel, D. M., Lissounov, A., Brzovic, P. S., and Klevit, R. E. (2011). Ubch7 Reactivity Profile Reveals Parkin and Hhari to Be Ring/Hect Hybrids. Nature 474, 105-108. doi: 10.1038/nature09966
Worthylake, D. K., Prakash, S., Prakash, L., and Hill, C. P. (1998). Crystal Structure of the Saccharomyces Cerevisiae Ubiquitin-Conjugating Enzyme Rad6 at 2.6 a Resolution. J. Biol. Chem. 273, 6271-6276. doi: 10.1074/ jbc.273.11.6271

Yada, M., Hatakeyama, S., Kamura, T., Nishiyama, M., Tsunematsu, R., Imaki, H., et al. (2004). Phosphorylation-Dependent Degradation of C-Myc Is Mediated by the F-Box Protein Fbw7. EMBO J. 23, 2116-2125. doi: 10.1038/ sj.emboj.7600217

Yang, J., Chen, D., Matar, K. A. O., Zheng, T., Zhao, Q., Xie, Y., et al. (2020). The Deubiquitinating Enzyme Moubp8 Is Required for Infection-Related Development, Pathogenicity, and Carbon Catabolite Repression in Magnaporthe Oryzae. Appl. Microbiol. Biotechnol. 104, 5081-5094. doi: 10.1007/s00253-020-10572-5

Yang, D., Hu, Y., Yin, Z., Gao, Q., Zhang, Y., Chan, F. Y., et al. (2020). Candida Albicans Ubiquitin and Heat Shock Factor-Type Transcriptional Factors Are Involved in 2-Dodecenoic Acid-Mediated Inhibition of Hyphal Growth. Microorganisms 8, 75. doi: 10.3390/microorganisms8010075

Yang, Y., Kitagaki, J., Dai, R. M., Tsai, Y. C., Lorick, K. L., Ludwig, R. L., et al. (2007). Inhibitors of Ubiquitin-Activating Enzyme (E1), a New Class of Potential Cancer Therapeutics. Cancer Res. 67, 9472-9481. doi: 10.1158/ 0008-5472.CAN-07-0568

Ye, Y., and Rape, M. (2009). Building Ubiquitin Chains: E2 Enzymes at Work. Nat. Rev. Mol. Cell Biol. 10, 755-764. doi: 10.1038/nrm2780

Yumimoto, K., and Nakayama, K. I. (2020). Recent Insight Into the Role of Fbxw7 as a Tumor Suppressor. Semin. Cancer Biol. 67, 1-15. doi: 10.1016/ j.semcancer.2020.02.017

Zhang, W., and Sidhu, S. S. (2014). Development of Inhibitors in the Ubiquitination Cascade. FEBS Lett. 588, 356-367. doi: 10.1016/j.febslet.2013.11.003

Zhao, J., Yang, Y., Fan, Y., Yi, J., Zhang, C., Gu, Z., et al. (2020). Ribosomal Protein L40e Fused With a Ubiquitin Moiety Is Essential for the Vegetative Growth, Morphological Homeostasis, Cell Cycle Progression, and Pathogenicity of Cryptococcus Neoformans. Front. Microbiol. 11, 570269. doi: 10.3389/ fmicb.2020.570269

Zheng, Q., Huang, T., Zhang, L., Zhou, Y., Luo, H., Xu, H., et al. (2016). Dysregulation of Ubiquitin-Proteasome System in Neurodegenerative Diseases. Front. Aging Neurosci. 8:303. doi: 10.3389/fnagi.2016.00303

Zhou, G. A., Chang, R. Z., and Qiu, L. J. (2010). Overexpression of Soybean Ubiquitin-Conjugating Enzyme Gene Gmubc2 Confers Enhanced Drought and Salt Tolerance Through Modulating Abiotic Stress-Responsive Gene Expression in Arabidopsis. Plant Mol. Biol. 72, 357-367. doi: 10.1007/ s11103-009-9575-x

Ziv, I., Matiuhin, Y., Kirkpatrick, D. S., Erpapazoglou, Z., Leon, S., Pantazopoulou, M., et al. (2011). A Perturbed Ubiquitin Landscape Distinguishes Between Ubiquitin in Trafficking and in Proteolysis. Mol. Cell Proteomics 10, M111 009753. doi: 10.1074/mcp.M111.009753

Conflict of Interest: The authors declare that the research was conducted in the absence of any commercial or financial relationships that could be construed as a potential conflict of interest.

Publisher's Note: All claims expressed in this article are solely those of the authors and do not necessarily represent those of their affiliated organizations, or those of the publisher, the editors and the reviewers. Any product that may be evaluated in this article, or claim that may be made by its manufacturer, is not guaranteed or endorsed by the publisher.

Copyright $\odot 2021$ Cao and Xue. This is an open-access article distributed under the terms of the Creative Commons Attribution License (CC BY). The use, distribution or reproduction in other forums is permitted, provided the original author(s) and the copyright owner(s) are credited and that the original publication in this journal is cited, in accordance with accepted academic practice. No use, distribution or reproduction is permitted which does not comply with these terms. 